\title{
Effect of Atomoxetine Treatment on Reading and Phonological Skills in Children with Dyslexia or Attention-Deficit/Hyperactivity Disorder and Comorbid Dyslexia in a Randomized, Placebo-Controlled Trial
}

\author{
Sally Shaywitz, MD, ${ }^{1}$ Bennett Shaywitz, MD, Linda Wietecha, BSN, MS, \\ Sharon Wigal, $\mathrm{PhD}^{3}$, Keith McBurnett, $\mathrm{PhD}^{4}$, David Williams, MS, \\ William G. Kronenberger, PhD, and Stephen R. Hooper, PhD ${ }^{7}$
}

\begin{abstract}
Objectives: Evaluated the effects of atomoxetine on the reading abilities of children with dyslexia only or attention-deficit/ hyperactivity disorder (ADHD) and comorbid dyslexia.

Methods: Children aged 10-16 years $(N=209)$ met Diagnostic and Statistical Manual of Mental Disorders, 4th Edition, Text Revision (DSM-IV-TR) criteria for dyslexia only $(n=58)$, ADHD and comorbid dyslexia $(n=124)$, or ADHD only $(n=27)$ and were of normal intelligence. Patients were treated with atomoxetine $(1.0-1.4 \mathrm{mg} / \mathrm{kg} / \mathrm{day})$ or placebo in a 16-week, randomized, placebo-controlled, double-blind trial. The dyslexia-only and ADHD and comorbid dyslexia groups were randomized 1:1; the ADHD-only group received atomoxetine in a blinded manner. Reading abilities were measured with the Woodcock Johnson III (WJIII), Comprehensive Test of Phonological Processing (CTOPP), Gray Oral Reading Tests-4, and Test of Word Reading Efficiency.

Results: Atomoxetine-treated dyslexia-only patients compared with placebo patients had significantly greater improvement $(p<0.02)$ with moderate to approaching high effect sizes (ES) on WJIII Word Attack (ES =0.72), Basic Reading Skills $(\mathrm{ES}=0.48)$, and Reading Vocabulary $(\mathrm{ES}=0.73)$. In the atomoxetine-treated ADHD and comorbid dyslexia group, improvement on the CTOPP Elision measure $(\mathrm{ES}=0.50)$ was significantly greater compared with placebo $(p<0.02)$. Total, inattentive, and hyperactive/impulsive ADHD symptom reductions were significant in the atomoxetine-treated ADHD and comorbid dyslexia group compared with placebo, and from baseline in the ADHD-only group $(p \leq 0.02)$. ADHD symptom improvements in the ADHD and comorbid dyslexia group were not correlated with improvements in reading.

Conclusions: Atomoxetine treatment improved reading scores in patients with dyslexia only and ADHD and comorbid dyslexia. Improvements for patients with dyslexia only were in critical components of reading, including decoding and reading vocabulary. For patients with ADHD and comorbid dyslexia, improvements in reading scores were distinct from improvement in ADHD inattention symptoms alone. These data represent the first report of improvements in reading measures following pharmacotherapy treatment in patients with dyslexia only evaluated in a randomized, double-blind trial.
\end{abstract}

Keywords: dyslexia, atomoxetine, reading, attention, vocabulary, comorbid dyslexia, ADHD

These data were presented, in part, at the American Academy of Child and Adolescent Psychiatry (AACAP) 59th Annual Meeting, San Francisco, CA; October 23-28, 2012.

${ }^{1}$ Yale Center for Dyslexia \& Creativity, New Haven, Connecticut.

${ }^{2}$ Eli Lilly and Company and/or one of its subsidiaries, Indianapolis, Indiana.

${ }^{3}$ AVIDA, Inc., Newport Beach, California.

${ }^{4}$ Department of Psychiatry, University of California, San Francisco, San Francisco, California.

5 inVentiv Health Clinical, Indianapolis, Indiana.

${ }^{6}$ Department of Psychiatry, Indiana University School of Medicine, Indianapolis, Indiana.

${ }^{7}$ School of Medicine, University of North Carolina, Chapel Hill, North Carolina.

Funding: This research study was funded and conducted by Lilly, USA, LLC.

(c) Sally Shaywitz et al. 2017; Published by Mary Ann Liebert, Inc. This Open Access article is distributed under the terms of the Creative Commons Attribution Noncommercial License (http://creativecommons.org/licenses/by-nc/4.0/) which permits any noncommercial use, distribution, and reproduction in any medium, provided the original author(s) and the source are credited. 


\section{Introduction}

D YSLEXIA (OR SPECIFIC READING DISABILITY) represents an unexpected difficulty in reading for an individual's age, intelligence, or professional status. Fluent reading-reading that is rapid, automatic, and with good intonation (prosody) - is very frequently affected, even in dyslexic readers who have learned to read accurately (Shaywitz 1998; Lyon et al. 2003; Ferrer et al. 2010). Dyslexia is highly prevalent and persistent and occurs worldwide. In the United States, dyslexia rates range from 5\% to 17.5\% (Felton et al. 1990; Bruck 1992; Francis et al. 1996; Shaywitz et al. 1999; Shaywitz 2003). Worldwide prevalence rates also are high, with rates ranging from $8 \%$ in mainland China to almost 13\% in Hong Kong (Chan et al. 2007; Liu et al. 2012).

At its core, dyslexia is primarily a problem with phonological processing (i.e., getting to the elemental sounds of spoken language) affecting both spoken and written language. To learn to read, the child has to develop the unconscious awareness that spoken words can be pulled apart into the elemental particles of speech (i.e., phonemes) and that the letters in a written word represent these sounds. Evidence from a number of lines of investigation provides overwhelming evidence that a deficit in phonology represents the most robust and specific correlate of dyslexia (Liberman and Shankweiler 1991; Morris et al. 1998; Shaywitz 1998, 2003).

In addition to the centrality of phonological mechanisms in dyslexia, recent evidence supports an important role for attentional mechanisms in dyslexia (Shaywitz and Shaywitz 2008; Kovelman et al. 2012). Cognitive studies suggest that attention is a critical, overlooked component facilitating the translation of print into speech and is particularly important for achieving fluent reading (Reynolds and Besner 2006). Further evidence that attentional processes may be important in reading comes from studies emphasizing the comorbidity of dyslexia and attention-deficit/hyperactivity disorder (ADHD) (August and Garfinkel 1990; Dykman and Ackerman 1991; Shaywitz et al. 1994; Willcutt and Pennington 2000; Germano et al. 2010; Yoshimasu et al. 2010). Estimates of rates in those with dyslexia and comorbid ADHD range from $9 \%$ to as high as $60 \%$, whereas patients initially diagnosed with ADHD have a co-occurrence of dyslexia reported to range from $15 \%$ to $45 \%$ (Willcutt and Pennington 2000; Willcutt et al. 2001; Carroll et al. 2005; Maughan and Carroll 2006; Sexton et al. 2012).

The role of attentional mechanisms in dyslexia is further supported by a recent functional magnetic resonance imaging connectivity analysis. Using data-driven brain parcellation, connectivity profiles were compared between dyslexic and typical readers. Relative to typical readers, those with dyslexia demonstrated decreased connectivity between posterior reading systems and prefrontal attentional regions (Finn et al. 2014).

The consequences of dyslexia have profound long-term impacts on the educational, employment, and health outcomes of children with dyslexia, all of which are significantly worse than for their typical reading peers. Thus, high school dropout rates for students classified as learning disabled $(80 \%-90 \%$ of whom are dyslexic) are three to four times as high as for typical readers (Blackorby and Wagner 1996). Furthermore, men and women with lower levels of literacy are more likely to be at or near national poverty levels. They tend to rely on public assistance to support themselves in contrast to those with higher levels of literacy who are significantly more likely to be employed and to avoid unemployment; to be active labor force participants; to be employed in professional, management-related, and technical (rather than service, craft, laborer/helper) occupations; to have supervisory responsibilities on their job; and to earn significantly more (two to three times more) weekly and annually (Kirsch et al. 1993; Reder and Vogel 1997; Rudd et al. 2004, 2007; Sum et al. 2004; Kutner et al. 2007; Tamassia et al. 2007; Bynner and Parsons 2009; Kruidenier et al. 2010). In addition, adults with low levels of literacy have difficulty accessing or understanding health-related information, are hospitalized more often, and do not manage chronic diseases as well (Rudd et al. 2004, 2007; Kutner et al. 2006). Overall, they are more likely to experience poor health and a shortened life span (Baker et al. 1997; Rudd et al. 2000; Kutner et al. 2006; Marcus 2006). A more recent study showed that the odds of dying among low-educated (no high school diploma) white women were significantly greater than among peers with a high school, college, or advanced degree (Montez and Zajacova 2013).

It has been known for over 2 decades that even with the best reading interventions, many first- and second-grade children with dyslexia fail to learn to read proficiently (Torgesen 2000). Most recently, a review of interventions for dyslexia found that the best current reading interventions have produced only limited success and that significant numbers of children receiving these interventions remain poor readers (Compton et al. 2014). Such discouraging findings mandate that other treatment modalities be developed.

Pharmacotherapy for ADHD is now more than 75 years old, while only recently have studies begun to examine potential pharmacological interventions for patients with dyslexia only and $\mathrm{ADHD}$ and comorbid dyslexia (ADHD+D). For example, reports in small samples that did not include dyslexia-only patients suggest that stimulants may have beneficial effects on reading in children with $\mathrm{ADHD}+\mathrm{D}$ (Grizenko et al. 2006; Keulers et al. 2007; Bental and Tirosh 2008; Williamson et al. 2014). Small clinical trials have also demonstrated improved reading scores in patients with $\mathrm{ADHD}+\mathrm{D}$ during treatment with atomoxetine (de Jong et al. 2009; Sumner et al. 2009; Wietecha et al. 2013).

The current study was designed to more comprehensively and systematically evaluate the efficacy of atomoxetine treatment in the dyslexia-only and ADHD $+\mathrm{D}$ adolescent populations by inclusion of a larger sample, a placebo control condition, and a longer trial duration. In a separate article, we reported the effects of atomoxetine on core symptoms of ADHD in pediatric patients with ADHD + D (Wietecha et al. 2013). The focus of this report is to evaluate the effect of atomoxetine compared to placebo on reading abilities of pediatric patients with dyslexia only or ADHD+D.

\section{Methods \\ Patients}

All patients with dyslexia only and ADHD $+\mathrm{D}$ met criteria for dyslexia at the second screening visit defined as follows: at least a 22-point discrepancy between the 4-subtest version of the Wechsler Abbreviated Scale of Intelligence (WASI) Verbal Intelligence Quotient (IQ) or Performance IQ (whichever was higher) and the Woodcock Johnson III (WJIII) Word Attack score, Word Identification score, or Basic Reading Skills score; or a standard score of 89 or lower $(<25$ th percentile) on the WJIII Word Attack score, Word Identification score, or Basic Reading Skills score 
(Weschler 1999; Woodcock et al. 2001). All patients with ADHD only and ADHD+D met Diagnostic and Statistical Manual of Mental Disorders, 4th Edition, Text Revision (DSM-IV-TR) (American Psychiatric Association 2000) diagnostic criteria for ADHD, confirmed during the first screening visit by administering the Kiddie Schedule for Affective Disorders and Schizophrenia for School-Age Children-Present and Lifetime Version-Behavioral component (Kaufman et al. 1997). In addition, patients with ADHD + D and ADHD only were required to have an AttentionDeficit/Hyperactivity Disorder Rating Scale-IV-Parent Version: Investigator-Administered and Scored (ADHDRS-IV-Parent:Inv) total score of at least 1.5 standard deviations above age and gender norms at the second and third screening visits (Faries et al. 2001). All patients had a standard score of at least 80 on the Full Scale IQ of the WASI at the first screening visit. Patients were 10 to 16 years old at the time of consent. Patients were excluded from the study if they had a documented history of bipolar I or bipolar II disorder, psychosis, autism, Asperger's syndrome, or pervasive developmental disorder, or were currently taking anticonvulsants for seizure control.

Parents or caretakers provided written consent for their children to participate in the study, and children also provided assent. The study protocol was approved by each site's ethics review board. This study was conducted in accordance with the ethical principles that have their origin in the Declaration of Helsinki and are consistent with good clinical practices and applicable laws and regulations.

\section{Study design}

The study was a multicenter outpatient, randomized, placebocontrolled, 16-week, double-blind, Phase 4 study of atomoxetine $(0.5 \mathrm{mg} /[\mathrm{kg} \cdot \mathrm{day}]$ for 3 days, then $1.0-1.4 \mathrm{mg} /[\mathrm{kg} \cdot \mathrm{day}])$ once daily in children and adolescents with dyslexia only, ADHD+D, or ADHD only conducted in the United States between 2008 and 2011. The detailed description of the study design and primary efficacy ADHD outcomes for this study has been reported in an earlier publication (Wietecha et al. 2013). Briefly, after an $\sim 2$-week-long screening phase, dyslexia-only and ADHD + D patients were randomized 1:1 to atomoxetine or placebo treatment for 16 weeks (acute treatment phase). All ADHD-only patients received atomoxetine for the 16-week acute phase. However, to mitigate potential treatment bias effects in the ADHD-only group, patients and site personnel were informed that assignment to placebo treatment was possible during the initial 16-week acute phase. After completing the acute treatment phase, patients were eligible to enter a 16-week, open-label extension phase in which all patients received atomoxetine. Only the reading outcome results from the 16-week, double-blind, placebo-controlled acute phase are presented.

\section{Efficacy measures}

The academic measures used in this study are validated and have well-documented test-retest reliability (Torgesen et al. 1999; Wagner et al. 1999; Wiederholt and Bryant 2001; Woodcock et al. 2001). Changes in reading skills were measured by the WJIII reading subtests and composite, the Comprehensive Test of Phonological Processing (CTOPP), the Gray Oral Reading Tests-4 (GORT-4), and the Test of Word Reading Efficiency (TOWRE) (Torgesen et al. 1999; Wagner et al. 1999; Wiederholt and Bryant 2001; Woodcock et al. 2001). Parallel forms for the WJIII, GORT4 , and TOWRE were alternated across targeted visits. The WJIII tasks included Word Identification, a measure of real word identification; Word Attack, a measure of pseudoword decoding; Spelling; Passage Comprehension; and Reading Vocabulary. Composite measures derived from these subtests include Basic Reading Skills, a combination of Word Identification and Word Attack, and Reading Comprehension, a combination of Passage Comprehension and Reading Vocabulary (Woodcock et al. 2001). The CTOPP assesses phonological awareness, phonological memory, and rapid naming (Wagner et al. 1999). The GORT-4 measures oral reading rate, accuracy, fluency, and comprehension (Wiederholt and Bryant 2001). The TOWRE is a measure of an individual's ability to pronounce printed words and nonwords accurately and fluently and contains two subtests: Sight Word Efficiency and Phonemic Decoding Efficiency. The TOWRE provides an assessment of speed and accuracy of visually based, context-free word reading skills (Torgesen et al. 1999).

Changes in ADHD symptoms from baseline to week 16 were assessed in all diagnostic groups using the ADHDRS-IV-Parent:Inv total and subscale scores.

\section{Statistical analyses}

All analyses of reading ability scores were done on an intentto-treat basis. Reading ability data were analyzed with lastobservation-carried-forward analyses using fixed-effects analysis of covariance (ANCOVA) models with terms for treatment group, study site, gender, and age. Type III sums of squares were used for between-treatment tests. Changes within treatment were assessed using Student's $t$-test applied to the least-squares mean (LSM) for the group from the ANCOVA model. All tests of treatment effects were conducted at a two-sided alpha level of 0.05. Effect sizes (ES) were calculated by dividing the treatment group differences in the LSM changes by the pooled standard deviation of the changes. Secondary endpoints were not adjusted for testing of multiple hypotheses, with the intention of showing the actual results that could identify areas in which more research could be warranted. Spearman correlation coefficients were determined between changes in ADHDRS-IV-Parent:Inv (Total and Inattentive and Hyperactive/Impulsive subscales), demographic baseline parameters (age, gender, ethnicity, income status, education, ADHD subtype), and all reading ability measures at 16 weeks. Categories of ethnicity were predefined by the sponsor.

The prespecified analysis for the trial was an ANCOVA model, with terms for treatment, study site, baseline score, gender, and age, on reading measures comparing atomoxetine and placebo in subjects with dyslexia only and ADHD $+\mathrm{D}$ after 16 weeks. A post hoc analysis was conducted to correct the adjustment for baseline scores, which may not have been an appropriate analysis as all patients did not have dyslexia and ADHD. In this post hoc analysis, the data were examined with the term for baseline score excluded from the model.

\section{Results}

\section{Demographics and safety}

The diagnostic sample of the 209 randomized patients who entered the acute phase included 58 with dyslexia only $(n=29$ atomoxetine; $n=29$ placebo), 124 with $\mathrm{ADHD}+\mathrm{D}(n=64$ atomoxetine; $n=60$ placebo), and 27 with ADHD only. In the atomoxetine group, $7.5 \%$ of patients discontinued due to an adverse event compared with $2.2 \%$ in the placebo group. A total of 86 patients in the atomoxetine group and 73 patients in the placebo group completed the study (Fig. 1). More than half the patients 


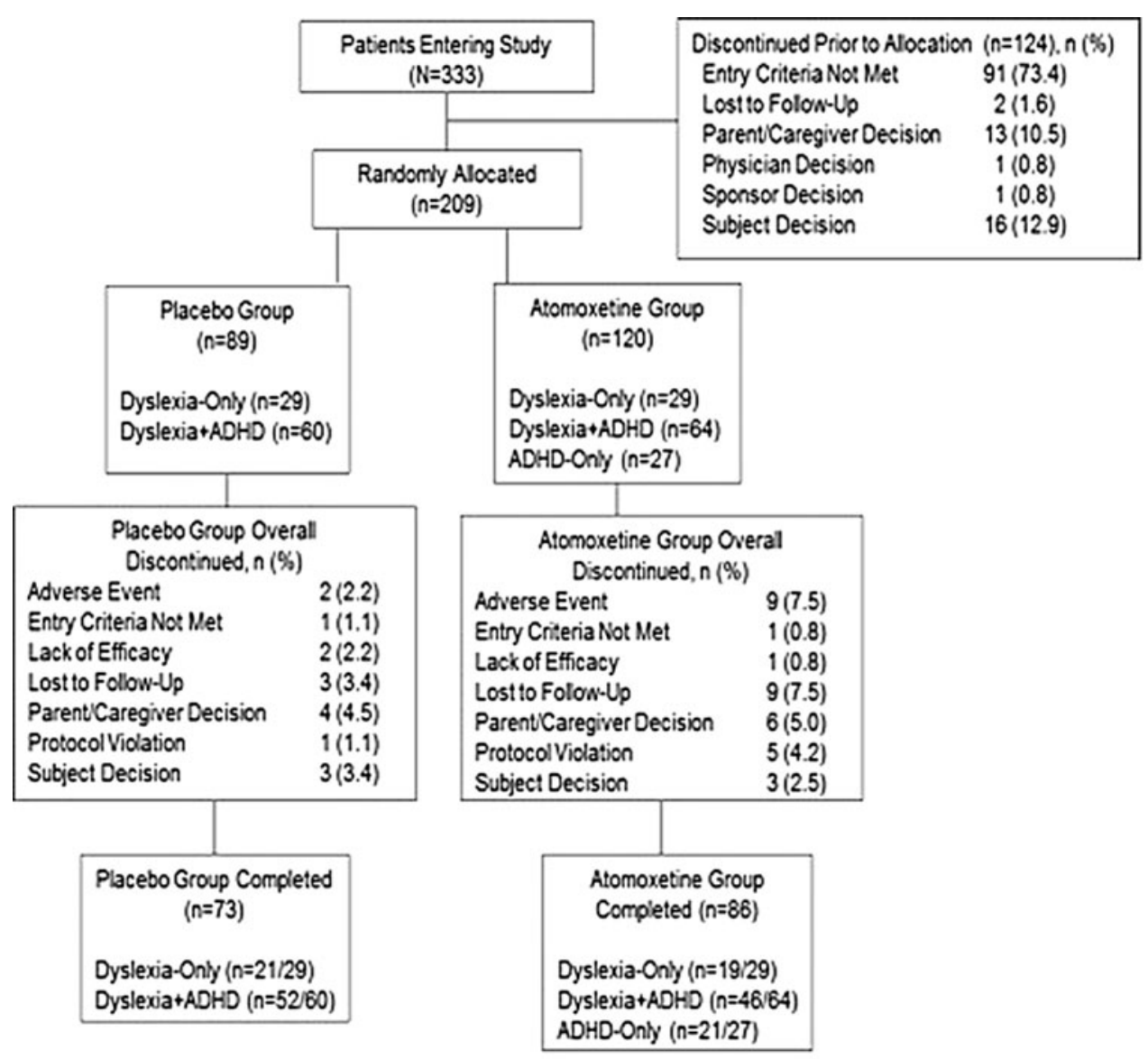

FIG. 1. Flow diagram of subject disposition by treatment and diagnostic category during 16-week, double-blind phase.

were male $(62 \%)$ with a mean age of 12 years (Table 1$)$. Nearly equal numbers of patients presented with the inattentive or combined ADHD subtypes and the distribution between treatment groups was similar. The baseline characteristics for educational services by diagnostic group are described in Supplementary
Table S1 (Supplementary Data are available online at www .liebertpub.com/cap).

More patients in the atomoxetine group experienced $\geq 1$ adverse event compared with placebo $(p=0.046)$ (Supplementary Table S2). The most common adverse events included nausea,

Table 1. Baseline Demographics and Characteristics

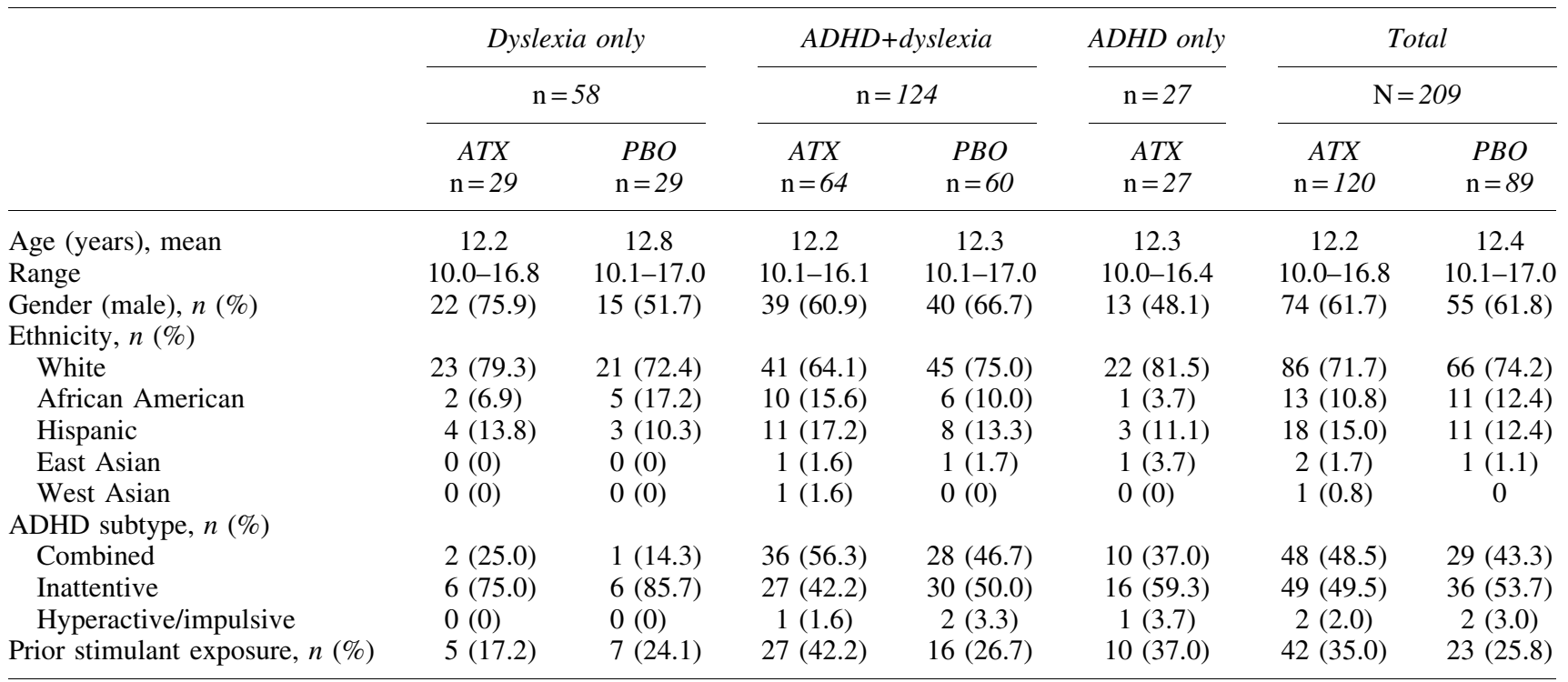

Demographics and characteristics may not have been reported for all patients included in the analyses.

$\mathrm{ADHD}$, attention-deficit/hyperactivity disorder; ATX, atomoxetine; $N$, overall number of patients in group; $n$, number of patients; PBO, placebo. 
Table 2. Changes in Reading Abilities-Baseline to Week 16

\begin{tabular}{|c|c|c|c|c|c|c|c|c|c|}
\hline \multirow[b]{2}{*}{ Measure } & \multirow[b]{2}{*}{$T x$} & \multicolumn{3}{|c|}{ Dyslexia } & \multicolumn{3}{|c|}{$A D H D+$ dyslexia } & \multicolumn{2}{|c|}{$A D H D$ only } \\
\hline & & Baseline & $\begin{array}{c}L S M \\
\text { change }^{\mathrm{a}}\end{array}$ & $\begin{array}{l}\text { Effect } \\
\text { size }\end{array}$ & Baseline & $\begin{array}{c}\text { LSM } \\
\text { change }^{\mathrm{a}}\end{array}$ & $\begin{array}{l}\text { Effect } \\
\text { size }\end{array}$ & Baseline & $\begin{array}{c}\text { LSM } \\
\text { change }\end{array}$ \\
\hline Woodcock Johnson III & & & $\begin{array}{l}\text { TX } n=19 \\
\text { BO } n=22\end{array}$ & & & $\begin{array}{l}\text { ATX } n=51 \\
\text { PBO } n=55\end{array}$ & & \multicolumn{2}{|c|}{$\operatorname{ATX} n=22$} \\
\hline Word Attack & $\begin{array}{l}\text { ATX } \\
\text { PBO }\end{array}$ & $\begin{array}{l}84.11 \\
88.05\end{array}$ & $\begin{array}{c}4.28 *^{\dagger} \\
-3.20^{*}\end{array}$ & 0.718 & $\begin{array}{l}84.82 \\
86.53\end{array}$ & $\begin{array}{l}2.38^{+} \\
1.25\end{array}$ & 0.137 & 101.91 & -1.20 \\
\hline Word Identification & $\begin{array}{l}\text { ATX } \\
\text { PBO }\end{array}$ & $\begin{array}{l}80.47 \\
83.86\end{array}$ & $\begin{array}{l}4.11 * \\
0.89\end{array}$ & 0.033 & $\begin{array}{l}81.45 \\
87.55\end{array}$ & $\begin{array}{r}0.30 \\
-1.25\end{array}$ & 0.183 & 101.50 & -0.56 \\
\hline Basic Reading Skills & $\begin{array}{l}\text { ATX } \\
\text { PBO }\end{array}$ & $\begin{array}{l}80.26 \\
84.77\end{array}$ & $\begin{array}{l}\mathbf{5 . 4 0} * *^{\dagger} \\
-0.52\end{array}$ & 0.478 & $\begin{array}{l}81.61 \\
85.82\end{array}$ & $\begin{array}{l}1.31 \\
0.22\end{array}$ & 0.137 & 101.95 & -0.85 \\
\hline Reading Vocabulary & $\begin{array}{l}\text { ATX } \\
\text { PBO }\end{array}$ & $\begin{array}{l}86.42 \\
90.91\end{array}$ & $\begin{array}{l}\mathbf{4 . 1 9} * \dagger \\
-2.97\end{array}$ & 0.731 & $\begin{array}{l}85.02 \\
85.84 \\
91.87\end{array}$ & $\begin{array}{l}-0.11^{+} \\
-1.10\end{array}$ & 0.074 & 96.05 & $-4.92 *$ \\
\hline Passage Comprehension & $\begin{array}{l}\text { ATX } \\
\text { PBO }\end{array}$ & $\begin{array}{l}83.74 \\
85.95\end{array}$ & $\begin{array}{r}-1.27 \\
0.21\end{array}$ & 0.112 & $\begin{array}{l}83.90 \\
88.45\end{array}$ & $\begin{array}{l}-2.88 \\
-3.63 *\end{array}$ & 0.010 & 97.14 & $-4.86 *$ \\
\hline Reading Comprehension & $\begin{array}{l}\text { ATX } \\
\text { PBO }\end{array}$ & $\begin{array}{l}82.58 \\
86.23\end{array}$ & $\begin{array}{r}2.13 \\
-1.33\end{array}$ & 0.270 & $\begin{array}{l}82.22 \\
88.45\end{array}$ & $\begin{array}{l}-1.60 \\
-3.14 *\end{array}$ & 0.111 & 95.86 & $-5.77 * *$ \\
\hline Reading Fluency & $\begin{array}{l}\text { ATX } \\
\text { PBO }\end{array}$ & $\begin{array}{l}84.95 \\
84.36\end{array}$ & $\begin{array}{r}0.63 \\
-0.62\end{array}$ & 0.130 & $\begin{array}{l}82.51 \\
89.09\end{array}$ & $\begin{array}{l}0.12 \\
0.02\end{array}$ & 0.015 & 95.95 & 1.54 \\
\hline Spelling & $\begin{array}{l}\text { ATX } \\
\text { PBO }\end{array}$ & $\begin{array}{l}77.32 \\
83.32\end{array}$ & $\begin{array}{l}-0.77 \\
-3.50\end{array}$ & 0.362 & $\begin{array}{l}79.06 \\
84.15\end{array}$ & $\begin{array}{c}0.19 \\
-3.60 *\end{array}$ & 0.394 & 100.50 & 0.04 \\
\hline Spelling of sounds & $\begin{array}{l}\text { ATX } \\
\text { PBO }\end{array}$ & $\begin{array}{l}84.95 \\
80.45\end{array}$ & $\begin{array}{r}-1.76 \\
6.45^{*}\end{array}$ & 0.504 & $\begin{array}{l}82.16 \\
80.69\end{array}$ & $\begin{array}{l}5.66^{* *} \\
3.86\end{array}$ & 0.161 & 88.23 & $9.58 * *$ \\
\hline $\begin{array}{l}\text { Comprehensive Test of } \\
\text { Phonological Processing }\end{array}$ & & & $\begin{array}{l}\text { TX } n=20 \\
\text { BO } n=22\end{array}$ & & & $\begin{array}{l}\text { ATX } n=51 \\
\operatorname{PBO} n=55\end{array}$ & & AT & $=22$ \\
\hline Elision & $\begin{array}{l}\text { ATX } \\
\text { PBO }\end{array}$ & $\begin{array}{l}7.10 \\
7.59\end{array}$ & $\begin{array}{r}0.03 \\
-0.36\end{array}$ & 0.097 & $\begin{array}{l}6.69 \\
7.69\end{array}$ & $\begin{array}{r}\mathbf{0 . 7 2} \mathbf{9}^{\dagger} \\
-0.46\end{array}$ & 0.499 & 9.55 & -0.01 \\
\hline Blending words & $\begin{array}{l}\text { ATX } \\
\text { PBO }\end{array}$ & $\begin{array}{l}8.65 \\
8.73\end{array}$ & $\begin{array}{l}2.00 * * \\
1.94 * * *\end{array}$ & 0.093 & $\begin{array}{l}9.27 \\
8.78\end{array}$ & $\begin{array}{l}0.97 * * \\
1.08 * * *\end{array}$ & 0.008 & 9.45 & $2.07 * * *$ \\
\hline Phonological awareness & $\begin{array}{l}\text { ATX } \\
\text { PBO }\end{array}$ & $\begin{array}{l}87.20 \\
87.45\end{array}$ & $\begin{array}{l}4.69 \\
5.15\end{array}$ & 0.022 & $\begin{array}{l}88.00 \\
89.15\end{array}$ & $\begin{array}{l}5.09 * * \\
1.87\end{array}$ & 0.343 & 96.59 & $6.31 *$ \\
\hline Memory for digits & $\begin{array}{l}\text { ATX } \\
\text { PBO }\end{array}$ & $\begin{array}{l}8.15 \\
7.73\end{array}$ & $\begin{array}{l}0.58 \\
0.00\end{array}$ & 0.148 & $\begin{array}{l}8.18 \\
7.96\end{array}$ & $\begin{array}{l}0.45^{+} \\
0.08\end{array}$ & 0.177 & 9.82 & -0.62 \\
\hline Nonword repetition & $\begin{array}{l}\text { ATX } \\
\text { PBO }\end{array}$ & $\begin{array}{l}8.75 \\
8.05\end{array}$ & $\begin{array}{l}1.14^{*} \\
0.67\end{array}$ & 0.108 & $\begin{array}{l}8.29 \\
8.69\end{array}$ & $\begin{array}{l}0.59 \\
0.45\end{array}$ & 0.032 & 9.09 & $1.02 *$ \\
\hline Phonological memory & $\begin{array}{l}\text { ATX } \\
\text { PBO }\end{array}$ & $\begin{array}{l}90.70 \\
85.82\end{array}$ & $\begin{array}{l}4.45 \\
4.24\end{array}$ & 0.112 & $\begin{array}{l}89.14 \\
90.07\end{array}$ & $\begin{array}{l}2.83 \\
1.00\end{array}$ & 0.122 & 97.82 & 1.51 \\
\hline Rapid letter ${ }^{\mathrm{b}}$ naming & $\begin{array}{l}\text { ATX } \\
\text { PBO }\end{array}$ & $\begin{array}{l}7.85 \\
7.73\end{array}$ & $\begin{array}{l}-0.14 \\
-0.94 *\end{array}$ & 0.515 & $\begin{array}{l}7.33 \\
7.84\end{array}$ & $\begin{array}{l}0.26 \\
0.21\end{array}$ & 0.041 & 8.68 & -0.02 \\
\hline Rapid digit ${ }^{\mathrm{b}}$ naming & $\begin{array}{l}\text { ATX } \\
\text { PBO }\end{array}$ & $\begin{array}{l}8.00 \\
7.14\end{array}$ & $\begin{array}{r}0.04 \\
-0.15\end{array}$ & 0.251 & $\begin{array}{l}7.30 \\
7.69\end{array}$ & $\begin{array}{l}0.31 \\
0.14\end{array}$ & 0.051 & 8.95 & 0.06 \\
\hline Rapid naming ${ }^{\mathrm{b}}$ & $\begin{array}{l}\text { ATX } \\
\text { PBO }\end{array}$ & $\begin{array}{l}87.55 \\
83.09\end{array}$ & $\begin{array}{l}-4.04 \\
-2.18\end{array}$ & 0.151 & $\begin{array}{l}84.14 \\
86.89\end{array}$ & $\begin{array}{l}1.62 \\
0.46\end{array}$ & 0.070 & 92.18 & -1.37 \\
\hline Gray Oral Reading Tests-4 & & & $\begin{array}{l}\text { TX } n=20 \\
\text { BO } n=22\end{array}$ & & & $\begin{array}{l}\mathrm{ATX} n=51 \\
\operatorname{PBO} n=55\end{array}$ & & AT & $=21$ \\
\hline Accuracy & $\begin{array}{l}\text { ATX } \\
\text { PBO }\end{array}$ & $\begin{array}{l}5.35 \\
5.50\end{array}$ & $\begin{array}{l}1.39 * * \\
0.73\end{array}$ & 0.181 & $\begin{array}{l}5.33 \\
6.31\end{array}$ & $\begin{array}{l}0.77 * \\
0.43\end{array}$ & 0.146 & 8.10 & 0.71 \\
\hline Rate & $\begin{array}{l}\text { ATX } \\
\text { PBO }\end{array}$ & $\begin{array}{l}5.65 \\
5.50\end{array}$ & $\begin{array}{l}1.21^{*} \\
0.72\end{array}$ & 0.204 & $\begin{array}{l}5.67 \\
6.98\end{array}$ & $\begin{array}{r}0.14 \\
-0.02\end{array}$ & 0.090 & 9.00 & 0.04 \\
\hline Fluency & $\begin{array}{l}\text { ATX } \\
\text { PBO }\end{array}$ & $\begin{array}{l}4.05 \\
4.18\end{array}$ & $\begin{array}{l}1.43 * * \\
1.18 * *\end{array}$ & 0.006 & $\begin{array}{l}4.33 \\
5.78\end{array}$ & $\begin{array}{l}0.78 \\
0.25\end{array}$ & 0.164 & 7.67 & 0.63 \\
\hline Comprehension & $\begin{array}{l}\text { ATX } \\
\text { PBO }\end{array}$ & $\begin{array}{l}7.80 \\
8.14\end{array}$ & $\begin{array}{l}0.30 \\
1.03\end{array}$ & 0.197 & $\begin{array}{l}8.14 \\
8.69\end{array}$ & $\begin{array}{l}0.24 \\
0.54\end{array}$ & 0.117 & 9.62 & -0.41 \\
\hline Oral reading quotient & $\begin{array}{l}\text { ATX } \\
\text { PBO }\end{array}$ & $\begin{array}{l}72.35 \\
77.50\end{array}$ & $\begin{array}{c}11.22 * \\
3.55\end{array}$ & 0.184 & $\begin{array}{l}76.41 \\
82.07\end{array}$ & $\begin{array}{r}-2.19 \\
2.25\end{array}$ & 0.199 & 91.86 & -1.04 \\
\hline TOWRE & & & $\begin{array}{l}\text { TX } n=22 \\
\text { BO } n=28\end{array}$ & & & $\begin{array}{l}\text { ATX } n=61 \\
\operatorname{PBO} n=57\end{array}$ & & AT & $=26$ \\
\hline Phonemic decoding & $\begin{array}{l}\text { ATX } \\
\text { PBO }\end{array}$ & $\begin{array}{l}81.45 \\
81.43\end{array}$ & $\begin{array}{l}0.81 \\
1.13\end{array}$ & 0.052 & $\begin{array}{l}80.98 \\
83.70\end{array}$ & $\begin{array}{l}2.48^{* *} \\
1.75^{*}\end{array}$ & 0.127 & 96.69 & 1.80 \\
\hline Sight word & $\begin{array}{l}\text { ATX } \\
\text { PBO }\end{array}$ & $\begin{array}{l}86.09 \\
84.50\end{array}$ & $\begin{array}{l}0.75 \\
0.08\end{array}$ & 0.025 & $\begin{array}{l}83.89 \\
87.25\end{array}$ & $\begin{array}{l}1.41 \\
1.19\end{array}$ & 0.035 & 94.88 & 0.52 \\
\hline Total TOWRE & $\begin{array}{l}\text { ATX } \\
\text { PBO }\end{array}$ & $\begin{array}{l}80.41 \\
79.54\end{array}$ & $\begin{array}{l}7.28 \\
0.64\end{array}$ & 0.344 & $\begin{array}{l}81.77 \\
82.61\end{array}$ & $\begin{array}{l}3.31 \\
8.11 * *\end{array}$ & 0.191 & 102.35 & -4.53 \\
\hline
\end{tabular}

Bolded values denote change in atomoxetine group was statistically significantly greater than placebo, $p<0.02$.

${ }^{a}$ LSM values were derived from a model comparing atomoxetine-treated patients with placebo-treated patients within the diagnostic group.

${ }^{\mathrm{b}} \mathrm{ADHD}+\mathrm{D}$ group only: Atomoxetine $n=49$ for rapid naming and rapid letter naming and $n=50$ for rapid digit naming.

Within-treatment group $p$-values: $* p \leq 0.05 ; * * p<0.01 ; * * p<0.001$. Within-group $p$-values are from $t$-tests on LSM change, ANCOVA model: Change $=$ treatment group+study site+gender+age (type III sums of squares).

${ }^{\dagger}$ ATX versus placebo $p<0.02$; ANCOVA model: Change = treatment group+study site+gender+age (type III sums of squares).

${ }^{\ddagger} p<0.05 \mathrm{ADHD}+\mathrm{D}$ (atomoxetine) versus ADHD (atomoxetine) $p$-value. $p$-Values are from the ANCOVA model: Change $=$ diagnostic group+study site+gender+age (type III sums of squares).

ADHD, attention-deficit/hyperactivity disorder; ANCOVA, analysis of covariance; ATX, atomoxetine; LSM, least-squares mean; $n$, number of patients; PBO, placebo; TOWRE, test of word reading efficiency; Tx, treatment. 


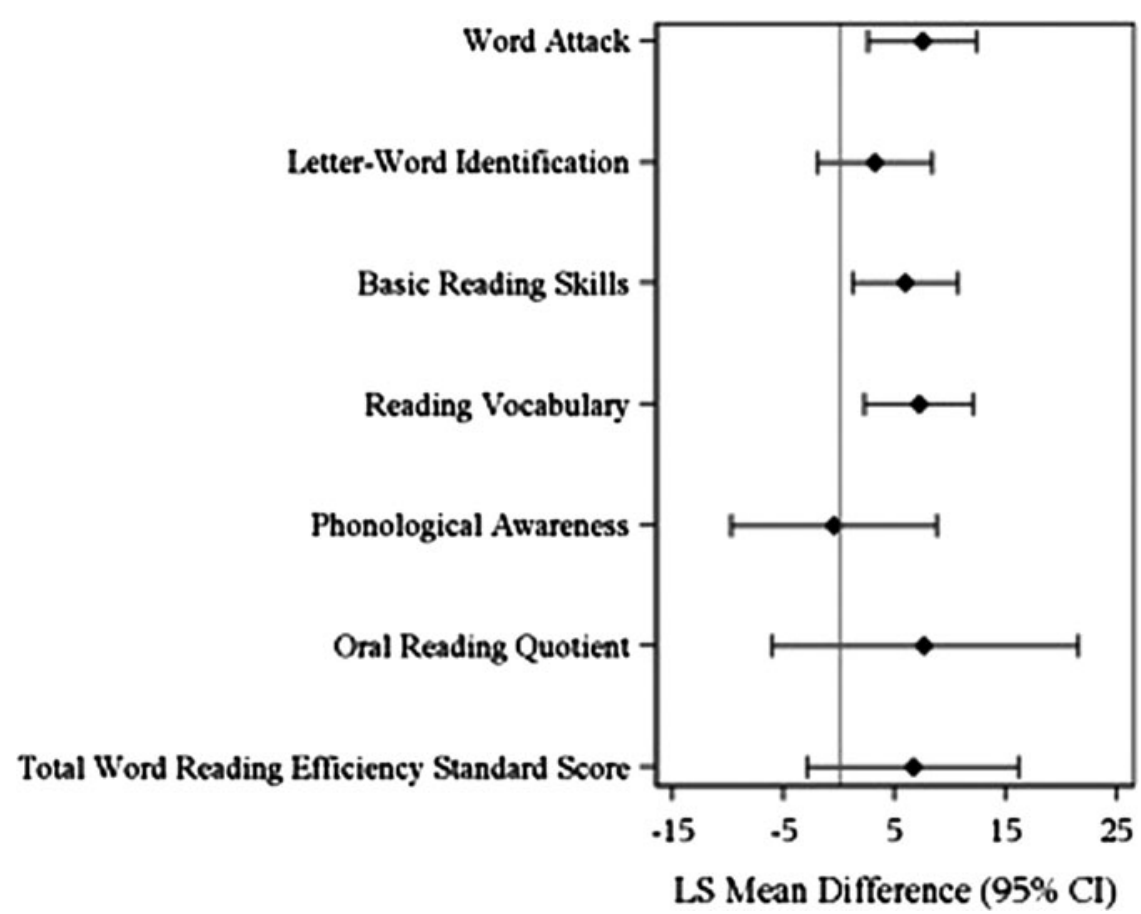

FIG. 2. Forest plot of reading measures for dyslexia patients treated with atomoxetine versus placebo. LSMs are raw means after adjustment for study site, gender, and age. Values analyzed by using a type III sums of squares, analysis of variance (ANOVA) model: variable $=$ treatment group+study site+gender+age. CI, confidence interval; LS, least squares.

fatigue, upper abdominal pain, decreased appetite, somnolence, and aggression. More detailed baseline demographics and characteristics and safety outcomes were reported in a previous publication (Wietecha et al. 2013).

\section{Reading ability}

The changes from baseline to 16 weeks and ES of treatment in reading abilities for each diagnostic group are shown in Table 2. Dyslexia-only patients in the atomoxetine group showed significantly greater gains $(p<0.02)$ in reading scores relative to the placebo group, with moderate to high treatment ES on WJIII measures of Word Attack $(\mathrm{ES}=0.72)$, Basic Reading Skills $(\mathrm{ES}=0.48)$, and Reading Vocabulary $(E S=0.73)$. In addition, within-group changes from baseline to 16 weeks in dyslexia-only patients with atomoxetine treatment were significant $(p<0.05)$ for several WJIII, CTOPP, and GORT-4 measures (Fig. 2).

Patients with $\mathrm{ADHD}+\mathrm{D}$ treated with atomoxetine showed greater improvement on the CTOPP Elision measure compared with placebo-treated patients $(p<0.02)$, with a moderate treatment ES $(E S=0.50)$. Comparisons of LSM changes in reading abilities between atomoxetine-treated patients with dyslexia only and $\mathrm{ADHD}+\mathrm{D}$ revealed no significant differences. However, atomoxetine-treated patients with $\mathrm{ADHD}+\mathrm{D}$ had significantly $(p<0.05)$ greater score increases on the WJIII Word Attack score and the CTOPP Memory for Digits score compared with the ADHD-only group. From baseline to 16 weeks, within-group LSM changes in the ADHD $+\mathrm{D}$ atomoxetine treatment group were significant for several WJIII, CTOPP, and TOWRE measures $(p<0.05)$. Results for patients with ADHD only showed significant within-group LSM changes from baseline to 16 weeks for limited WJIII and CTOPP measures $(p<0.05)$.

\section{Correlation between improvement in reading scores and improvement in attention measures}

After 16 weeks of treatment, ADHD symptom improvements in the ADHD + D group were not correlated with improvements in reading (data not shown). Furthermore, improvements in reading measures and ADHD symptoms were not significantly correlated with demographic parameters, including age, gender, income status, education, and ADHD subtype.

\section{ADHD symptom efficacy results}

ADHD symptom decreases from baseline on the primary efficacy measure total and subtype core ADHD symptoms after 16 weeks of double-blind treatment were significantly greater for patients treated with atomoxetine who had ADHD + D compared with placebo $(p \leq 0.02)$ (Supplementary Table S3). Similarly, patients with ADHD only demonstrated significant decrease in ADHD symptoms from baseline to 16 weeks $(p \leq 0.02)$. As would be expected, patients with dyslexia only had no significant LSM withingroup changes from baseline to 16 weeks or significant differences between treatment groups. Greater detail of efficacy results are published elsewhere (Wietecha et al. 2013).

\section{Discussion}

In this randomized, placebo-controlled trial, atomoxetine treatment resulted in significant improvements on multiple measures of reading in children and adolescents with dyslexia only or $\mathrm{ADHD}+\mathrm{D}$. These results are particularly interesting in the older age group recruited here because reading interventions are considerably more effective in the early grades of school (Torgesen et al. 2001). In particular, for patients with dyslexia only, 
atomoxetine treatment over the 16-week period resulted in significant improvement in Word Attack, Basic Reading, and Reading Vocabulary on the WJIII, with moderate-to-large ES. In patients with ADHD $+\mathrm{D}$, atomoxetine treatment resulted in a significant improvement in phonological processing as measured by Elision on the CTOPP, with a moderate ES. Importantly, the improvements measured by ES achieved after 16 weeks of atomoxetine treatment are greater or comparable to those observed with traditional and more labor-intensive interventions (National Reading Panel 2000).

In this study, in patients with $\mathrm{ADHD}+\mathrm{D}$, baseline-to-endpoint within-group improvements were achieved on some WJIII subtests and other reading measures and separated from placebo on the CTOPP Elision score. The magnitude of change on reading measures was modest but is very relevant for proof of concept (e.g., that dyslexia can be improved with a medication). Changes represent approximately one-third of a standard deviation change. It remains to be seen if this positive change, in turn, creates other positive downstream effects in reading skills. Of course, additional research is necessary to better understand whether the magnitude of change is clinically significant. These improvements in reading measures were not correlated to improvement in overall ADHD symptoms or changes in the inattentive symptoms. These results suggest that the improvement in reading may not have been simply due to a reduction in ADHD symptomatology. Furthermore, the reading performance improvements were consistent with results from previous, smaller studies in atomoxetine-treated children with ADHD + D (de Jong et al. 2009; Sumner et al. 2009; Shaywitz et al. 2014). As in previous atomoxetine studies, the improvements in ADHD symptoms, overall and for the inattentive and hyperactive/impulsive subtypes, did not correlate with increases in reading scores or academic achievement (Weiss et al. 2007; de Jong et al. 2009; Sumner et al. 2009).

When considering improvement in phonological processing and reading skills, one must also take into account the important role of working memory (short-term memory in the context of other concurrent mental operations) in all types of language processing. In a prior article using the current data set (Wietecha et al. 2013), we demonstrated improvement in some areas of working memory in an $\mathrm{ADHD}+\mathrm{D}$ sample following treatment with atomoxetine. However, working memory improvement does not appear to be related to reading improvement in the present data, based on nonsignificant correlations between improvement in reading skills and ADHD symptoms (including attention and mental effort, which are highly related to working memory). However, because working memory is an important component of executive and language functioning and is impaired in patients with ADHD only and ADHD $+\mathrm{D}$, further research to elucidate the working memoryreading outcome relationship in the context of medication treatment is warranted.

We note several limitations of the current results. First, in the study of dyslexia, an inherent design limitation is the selection of any operational definition, as it may have an impact on results. It is widely agreed that not every child with dyslexia demonstrates a discrepancy between reading achievement skills or phonological processing and IQ. The mechanism resulting in poor reading and phonological skills may also contribute to lower IQ scores. In this study, the operational definition of dyslexia was conservative by allowing for both a discrepancy and a low achievement. Second, many of the statistical analyses were performed without correction for baseline scores. The a priori-specified analysis for adjustment of baseline scores may not have been an appropriate analysis for the primary ADHD efficacy measures as all patients did not have ADHD. Therefore, this adjustment may have obscured a difference by using an overall mean across diagnoses in calculation of LS means, thereby inflating the scores in the dyslexia-only group up to levels consistent with the ADHD +D group. Third, the effects of the baseline adjustment may have been over-influenced by ADHD $+\mathrm{D}$ patients, given the larger variability of baseline values for this group of patients. To account for this potentially limiting factor, the data were examined with the adjustment for baseline score excluded from the model in the post hoc analysis. Similarly, the reading measures were also reanalyzed excluding the baseline adjustment from the model, since differences may have been obscured by using an overall mean across diagnoses.

The data from this well-controlled study offer novel and compelling evidence to suggest that atomoxetine treatment improved reading outcomes in adolescents with dyslexia only and with comorbid ADHD and dyslexia over a 16-week treatment period. As noted earlier, many reading researchers have become disappointed with the results of traditional reading intervention programs that "...can best be described as producing limited successes" (Compton et al. 2014). At the same time, we emphasize that children with dyslexia must be taught to read and that atomoxetine treatment could serve as an effective pharmacologic adjunct to these more traditional school-based reading interventions. The substantial lifelong negative impact of dyslexia on many of the most critical factors influencing a person's life-education, employment, health-presents a powerful argument that potential additions to the armamentarium to improve reading in those who have dyslexia-in this case, pharmacotherapy-not be overlooked. These findings provide proof of concept for this aim as well as potential relief for the larger public health concerns related to dyslexia.

\section{Conclusions}

Atomoxetine treatment improved reading scores in patients with dyslexia only and in a randomized, double-blind trial. Improvements for patients with dyslexia only were in critical components of reading, including decoding and reading vocabulary. For patients with dyslexia and comorbid ADHD, improvements in reading scores were distinct from improvement in ADHD inattention symptoms alone.

\section{Clinical Significance}

This study adds important new information for the treatment of dyslexia as follows: (1) uses a randomized, double-blind placebo control design; (2) demonstrates that, in children with dyslexia, atomoxetine exerts significant positive effects on reading and phonological processing presumably by influencing prefrontal attentional mechanisms which then influence phonological processing; and (3) suggests that this treatment may serve as a new and useful adjunct to current therapy for dyslexia.

\section{Acknowledgments}

Role of the Sponsor: Lilly, USA, LLC participated in the design, conduct, collection, management, analysis, and interpretation of the data and in the preparation, review, and approval of the manuscript and decision to submit the manuscript for publication.

The authors thank Millie S. Hollandbeck for manuscript preparation and Courtneay Parsons and Morgan Weaver for editing 
assistance; Synchrogenix, a Certara Company (formerly ClinGenuity, LLC).

Clinical trial registration: NCT00607919, www.clinicaltrials.gov

\section{Authors' Contributions}

Sally Shaywitz and Bennett Shaywitz in addition to all authors had full access to all the data in the study and take responsibility for the integrity of the data and the accuracy of the data analysis. David Williams, a statistician with inVentiv Health, conducted and is responsible for the data analysis. The manuscript was written by Sally Shaywitz, Bennett Shaywitz, Millie Hollandbeck (contracted medical writer) and Linda Wietecha. David Williams, Sharon Wigal, Keith McBurnett, William Kronenberger, and Stephen Hooper reviewed and made significant contributions to all drafts and the final manuscript.

\section{Disclosures}

Sally Shaywitz, Bennett Shaywitz-Research support: Eli Lilly and Company.

Linda Wietecha-An employee and minor shareholder of Eli Lilly and Company and/or one of its subsidiaries.

Sharon Wigal-Research support: Addrenex Pharmaceuticals, Inc.; Eli Lilly and Company; Ironshore Pharmaceutical and Development, Inc.; McNeil Consumer Healthcare; NextWave Pharmaceuticals, Inc.; National Institute of Child Health and Human Development; Noven Pharmaceuticals, Inc.; Otsuka America Pharmaceutical, Inc.; Pfizer, Inc.; PsychoGenics; Quintiles, Inc.; Rhodes Pharmaceuticals, L.P.; Shionogi \& Co. Ltd.; Shire; Sunovion Pharmaceuticals, Inc.; and Tris Pharma, Inc. Consultant: Eli Lilly and Company; Ironshore Pharmaceutical and Development, Inc.; McNeil Consumer Healthcare; NextWave Pharmaceuticals, Inc; National Institutes of Health; Noven Pharmaceuticals, Inc.; NuTec Systems, Inc.; Pfizer, Inc.; Shire; Sunovion Pharmaceuticals, Inc; Taisho Pharmaceutical Co., Ltd.; and Tris Pharma, Inc. Speaker's bureau: McNeil Consumer Healthcare; Noven Pharmaceuticals, Inc.; Shionogi \& Co. Ltd.; and Shire.

Keith McBurnett-Research support: Abbott; Johnson \& Johnson; National Institute of Mental Health; Cephalon, Inc.; New River Pharmaceuticals, Inc.; Otsuka America Pharmaceutical, Inc.; Sigma Tau Pharmaceuticals, Inc.; Eli Lilly and Company; McNeil Pharmaceutical; and Shire. Consultant: Lexicor Medical Technology, Eli Lilly and Company, McNeil Pharmaceuticals, and Shire Pharmaceuticals. Honorarium: Received from Lexicon Pharmaceuticals, Inc.

David W. Williams - A full-time employee of inVentiv Health Clinical, LLC, and was a full-time employee of Eli Lilly and Company until October 2010.

William G. Kronenberger-Research support: Eli Lilly and Company, GlaxoSmithKline Plc, Supernus Pharmaceuticals, Inc., Center for Successful Parenting, National Institutes of Health: National Institute on Deafness and Other Communication Disorders and National Library of Medicine, Indiana University, and Indiana Clinical and Translational Sciences Institute. Consultant: Indiana Hemophilia and Thrombosis Center.

Stephen R. Hooper-Research support: Eli Lilly and Company, U.S. Department of Education Institute of Education Sciences, U.S. Department of Health and Human Services: Maternal and Child Health Bureau, National Institutes of Health: Administration on Developmental Disabilities, National Institute on Deafness and Other Communication Disorders, National Institute on Drug
Abuse, National Institute of Diabetes and Digestive and Kidney Diseases, and National Institute of Mental Health. Consultant: Eli Lilly and Company.

\section{References}

American Psychiatric Association: Diagnostic and Statistical Manual of Mental Disorders. 4th ed., Text Revision. Washington, DC: American Psychological Association; 2000.

August GJ, Garfinkel BD: Comorbidity of ADHD and reading disability among clinic-referred children. J Abnorm Child Psychol 18:29-45, 1990.

Baker DW, Parker RM, Williams MV, Clark WS, Nurss J: The relationship of patient reading ability to self-reported health and use of health services. Am J Public Health 87:10271030, 1997.

Bental B, Tirosh E: The effects of methylphenidate on word decoding accuracy in boys with attention-deficit/hyperactivity disorder. J Clin Psychopharmacol 28:89-92, 2008.

Blackorby J, Wagner M: Longitudinal postschool outcomes of youth with disabilities: Findings from the National Longitudinal Transition Study. Except Child 62:399-413, 1996.

Bruck M: Persistence of dyslexics' phonological awareness deficits. Dev Psychol 28:874-886, 1992.

Bynner J, Parsons S: Insights into basic skills from a UK longitudinal study. In: Tracking Adult Literacy and Numeracy Skills: Findings from Longitudinal Research. Edited by Reder S, Bynner J. New York, Routledge, 2009, pp. 27-58.

Carroll J, Maughan B, Goodman R, Meltzer H: Literacy difficulties and psychiatric disorders: Evidence for comorbidity. J Child Psychol Psychiatry 46:524-532, 2005.

Chan DW, Ho CS, Tsang S, Lee S, Chung KH: Prevalence, gender ratio and gender differences in reading-related cognitive abilities among Chinese children with dyslexia in Hong Kong. Educ Stud 33:249-265, 2007.

Compton DL, Miller AC, Elleman AM, Steacy LM: Have we forsaken reading theory in the name of "quick fix" interventions for children with reading disability? Sci Stud Read 18:55-73, 2014.

de Jong CG, Van De Voorde S, Roeyers H, Raymaekers R, Allen AJ, Knijff S, Verhelst H, Temmink AH, Smit LM, Rodriques-Pereira R, Vandenberghe D, van Welsen I, ter Schuren L, Al-Hakim M, Amin A, Vlasveld L, Oosterlaan J, Sergeant JA: Differential effects of atomoxetine on executive functioning and lexical decision in attentiondeficit/hyperactivity disorder and reading disorder. J Child Adolesc Psychopharmacol 19:699-707, 2009.

Dykman RA, Ackerman PT: Attention deficit disorder and specific reading disability: Separate but often overlapping disorders. J Learn Disabil 24:96-103, 1991.

Faries DE, Yalcin D, Harder D, Heiligenstein JH: Validation of the ADHD Rating Scale as a clinician administered and scored instrument. J Atten Disord 2:107-115, 2001.

Felton RH, Naylor CE, Wood FB: Neuropsychological profile of adult dyslexics. Brain Lang 39:485-497, 1990.

Ferrer E, Shaywitz BA, Holahan JM, Marchione K, Shaywitz SE: Uncoupling of reading and IQ over time: Empirical evidence for a definition of dyslexia. Psychol Sci 21:93-101, 2010.

Finn ES, Shen X, Holahan JM, Scheinost D, Lacadie C, Papademetris X, Shaywitz SE, Shaywitz BA, Constable RT: Disruption of functional networks in dyslexia: A whole-brain, data-driven analysis of connectivity. Biol Psychiatry 76:397-404, 2014.

Francis DJ, Shaywitz SE, Stuebing KK, Shaywitz BA, Fletcher JM: Developmental lag versus deficit models of reading disability: A longitudinal, individual growth curves analysis. J Educ Psychol 88: 3-17, 1996. 
Germano E, Gagliano A, Curatolo P: Comorbidity of ADHD and dyslexia. Dev Neuropsychol 35:475-493, 2010.

Grizenko N, Bhat M, Schwartz G, Ter-Stepanian M, Joober R: Efficacy of methylphenidate in children with attention-deficit hyperactivity disorder and learning disabilities: A randomized crossover trial. J Psychiatry Neurosci 31:46-51, 2006.

Kaufman J, Birmaher B, Brent D, Rao U, Flynn C, Moreci P, Williamson D, Ryan N: Schedule for Affective Disorders and Schizophrenia for School-Age Children-Present and Lifetime version (K-SADS-PL): Initial reliability and validity data. J Am Acad Child Adolesc Psychiatry 36:980-988, 1997.

Keulers EH, Hendriksen JG, Feron FJ, Wassenberg R, WuismanFrerker MG, Jolles J, Vles JS: Methylphenidate improves reading performance in children with attention deficit hyperactivity disorder and comorbid dyslexia: An unblinded clinical trial. Eur J Paediatr Neurol 11:21-28, 2007.

Kirsch I, Jungeblut A, Jenkins L, Kolstad A: Adult Literacy in America: A First Look at the Results of the National Adult Literacy Survey. Washington, DC: National Center for Education Statistics, US Department of Education, 1993.

Kovelman I, Norton ES, Christodoulou JA, Gaab N, Lieberman DA, Triantafyllou C, Wolf M, Whitfield-Gabrieli S, Gabrieli JD: Brain basis of phonological awareness for spoken language in children and its disruption in dyslexia. Cereb Cortex 22:754-764, 2012.

Kruidenier JR, MacArthur CA, Wrigley HS: Adult Education Literacy Instruction: A Review of the Research. Washington (District of Columbia), National Institute for Literacy, 2010.

Kutner M, Greenberg E, Jin Y, Paulsen C: The Health Literacy of America's Adults: Results from the 2003 National Assessment of Adult Literacy (NCES 2006-483). National Center for Education Statistics, US Department of Education, Washington, DC, 2006.

Kutner M, Greenberg E, Jin Y, Boyle B, Hsu Y, Dunleavy E: Literacy in Everyday Life: Results from the 2003 National Assessment of Adult Literacy (NCES 2007-480). National Center for Education Statistics, US Department of Education, Washington, DC, 2007.

Liberman IY, Shankweiler D: Phonology and beginning reading: A tutorial. In: Learning to Read: Basic Research and Its Implications. Edited by Rieben L, Perfetti CA. Mahwah (New Jersey), Lawrence Erlbaum Associates, 1991, pp. 3-17.

Liu L, Wang W, You W, Li Y, Awati N, Zhao X, Booth JR, Peng D: Similar alterations in brain function for phonological and semantic processing to visual characters in Chinese dyslexia. Neuropsychologia 50:2224-2232, 2012.

Lyon GR, Shaywitz SE, Shaywitz BA: A definition of dyslexia. Ann Dyslexia 53:1-14, 2003.

Marcus EN: The silent epidemic-The health effects of illiteracy. N Engl J Med 355:339-341, 2006.

Maughan B, Carroll J: Literacy and mental disorders. Curr Opin Psychiatry 19:350-354, 2006.

Montez JK, Zajacova A: Explaining the widening education gap in mortality among U.S. white women. J Health Soc Behav 54:166182, 2013.

Morris RD, Stuebing KK, Fletcher JM, Shaywitz SE, Lyon GR, Shankweiler DP, Katz L, Francis DJ, Shaywitz BA: Subtypes of reading disability: Variability around a phonological core. J Educ Psychol 90:347-373, 1998.

National Reading Panel: Teaching children to read: An evidencebased assessment of the scientific research literature on reading and its implications for reading instruction. Reports of the Subgroups, 2000. Available at www.nichd.nih.gov/publications/pubs/nrp/ Documents/report.pdf (last accessed March 18, 2014)

Reder S, Vogel SA: Lifespan employment and economic outcomes for adults with self-reported learning disabilities. In: Learning Dis- abilities and Employment. Edited by Gerber PJ, Brown DS. Austin (Texas), PRO-ED, 1997, pp. 371-394.

Reynolds M, Besner D: Reading aloud is not automatic: Processing capacity is required to generate a phonological code from print. J Exp Psychol Hum Percept Perform 32:1303-1323, 2006.

Rudd RE, Anderson JE, Oppenheimer S, Nath C: Health literacy: An update of medical and public health literature. In: Review of Adult Learning and Literacy, volume 7: Connecting Research, Policy, and Practice. Edited by Comings J, Garner B, Smith C. Mahwah (New Jersey), Lawrence Erlbaum Associates, 2007, pp. 175-203.

Rudd RE, Kirsch IS, Yamamoto K: Literacy and Health in America. Princeton (New Jersey), Educational Testing Service, 2004.

Rudd RE, Moeykens BA, Colton TC: Health and literacy: A review of medical and public health literature. In: Annual Review of Adult Learning and Literacy. Edited by Comings J, Garner B, Smith C. Mahwah (New Jersey), Lawrence Erlbaum Associates, 2000, pp. $158-199$.

Sexton CC, Gelhorn HL, Bell JA, Classi PM: The co-occurrence of reading disorder and ADHD: Epidemiology, treatment, psychosocial impact, and economic burden. J Learn Disabil 45:538-564, 2012.

Shaywitz BA, Shaywitz SE, Williams DW, Fox BK, Wietecha LA: Reading outcomes of children and adolescents with attentiondeficit/hyperactivity disorder and dyslexia following atomoxetine treatment. J Child Adolesc Psychopharmacol 24:419-425, 2014.

Shaywitz S: Overcoming Dyslexia: A New and Complete ScienceBased Program for Reading Problems at Any Level. New York, Alfred A. Knopf, 2003.

Shaywitz S, Fletcher J, Shaywitz B: Issues in the definition and classification of attention deficit disorder. Top Lang Disord 14: 1-25, 1994.

Shaywitz SE: Dyslexia. N Engl J Med 338:307-312, 1998.

Shaywitz SE, Fletcher JM, Holahan JM, Shneider AE, Marchione KE, Stuebing KK, Francis DJ, Pugh KR, Shaywitz BA: Persistence of dyslexia: The Connecticut Longitudinal Study at adolescence. Pediatrics 104:1351-1359, 1999.

Shaywitz SE, Shaywitz BA: Paying attention to reading: The neurobiology of reading and dyslexia. Dev Psychopathol 20:1329-1349, 2008.

Sum A, Kirsch I, Yamamoto K: A Human Capital Concern: The Literacy Proficiency of U.S. Immigrants. Princeton (New Jersey), Educational Testing Service, 2004.

Sumner CR, Gathercole S, Greenbaum M, Rubin R, Williams D, Hollandbeck M, Wietecha L: Atomoxetine for the treatment of attention-deficit/hyperactivity disorder (ADHD) in children with ADHD and dyslexia. Child Adolesc Psychiatry Ment Health 3:40, 2009.

Tamassia C, Lennon M, Yamamoto K, Kirsch IS: Adult Literacy in America: A First Look at Results from the Adult Education Program and Learner Surveys. Princeton (New Jersey), Educational Testing Service, 2007.

Torgesen JK: Individual differences in response to early interventions in reading: The lingering problem of treatment resisters. Learn Disabil Res Pract 15:55-64, 2000.

Torgesen JK, Alexander AW, Wagner RK, Rashotte CA, Voeller KKS, Conway T: Intensive remedial instruction for children with severe reading disabilities: Immediate and long-term outcomes from two instructional approaches. J Learn Disabil 34:3358, 2001.

Torgesen JK, Wagner RK, Rashotte CA: Test of Word Reading Efficiency (TOWRE) Examiner's Manual. Austin (Texas), PRO-ED, 1999. 
Wagner RK, Torgesen JK, Rashotte CA: Comprehensive Test of Phonological Processing (CTOPP) Examiner's Manual. Austin (Texas), PRO-ED, 1999.

Wechsler D: Wechsler Abbreviated Scale of Intelligence (WASI). San Antonio (Texas), The Psychological Corporation, 1999.

Weiss M, Lee B, Turgay A, Chang S, White H, Davis L, Wasdell M, Yoshioka A, Dickson R: Atomoxetine treatment: Correlations of ADHD, academic, cognitive, and functional outcomes. Poster presented at the 57th Annual Meeting of the Canadian Psychiatric Association, 2007 (poster).

Wiederholt JL, Bryant BR: Gray Oral Reading Tests (GORT-4) Examiner's Manual. Austin (Texas), PRO-ED, 2001.

Wietecha L, Williams D, Shaywitz S, Shaywitz B, Hooper SR, Wigal SB, Dunn D, McBurnett K: Atomoxetine improved attention in children and adolescents with attention-deficit/hyperactivity disorder and dyslexia in a 16 week, acute, randomized, double-blind trial. J Child Adolesc Psychopharmacol 23:605-613, 2013.

Willcutt EG, Pennington BF: Psychiatric comorbidity in children and adolescents with reading disability. J Child Psychol Psychiatry 41:1039-1048, 2000.

Willcutt EG, Pennington BF, Boada R, Ogline JS, Tunick RA, Chhabildas NA, Olson RK: A comparison of the cognitive deficits in reading disability and attention-deficit/hyperactivity disorder. $\mathbf{J}$ Abnorm Psychol 110:157-172, 2001.

Williamson D, Murray DW, Damaraju CV, Ascher S, Starr HL: Methylphenidate in children with ADHD with or without learning disability. J Atten Disord 18:95-104, 2014.

Woodcock RW, McGrew KS, Mather N: Woodcock Johnson III Tests of Achievement. Itasca (Illinois), Riverside Publishing, 2001.

Yoshimasu K, Barbaresi WJ, Colligan RC, Killian JM, Voigt RG, Weaver AL, Katusic SK: Gender, attention-deficit/hyperactivity disorder, and reading disability in a population-based birth cohort. Pediatrics 126:e788-e795, 2010.

Address correspondence to: Sally Shaywitz, MD Yale Center for Dyslexia \& Creativity 129 York St., Suite 1P New Haven, CT 06511

E-mail: sally.shaywitz@yale.edu 